\title{
ISU KONSERVASI LINGKUNGAN PADA KEGIATAN PARIWISATA DI KABUPATEN PADANG PARIAMAN
}

\author{
Nofriya ${ }^{1)}$, Ahmad Fadhly ${ }^{2)}$ \\ ${ }^{1}$ Program Studi Teknik Lingkungan, Sekolah Tinggi Teknologi Industri Padang \\ ${ }^{2}$ Program Studi Teknik Pertambangan, Sekolah Tinggi Teknologi Industri Padang \\ email: nofriyafirdaus@gmail.com
}

\begin{abstract}
Abstrak
Abstrak: Kegiatan pariwisata akan memiliki dampak terhadap lingkungan sehingga diperlukan komitmen untuk melaksanakan konservasi lingkungan yang disesuaikan dengan jenis objek wisata. Konsep pariwisata berkelanjutan merupakan salah satu komponen yang digunakan dalam peningkatan pemahaman mengenai pentingnya menjaga lingkungan dalam kegiatan wisata. Hal ini sesuai dengan regulasi yang telah dibuat oleh Kementerian Pariwisata dan Pemerintah Provinsi Sumatera Barat. Indikator konservasi lingkungan merupakan kegiatan menjaga dan meningkatkan kualitas lingkungan daerah wisata. Tujuan penelitian ini adalah untuk menganalisis kegiatan kerjasama antar pemangku kepentingan untuk menjaga kelestarian lingkungan, pelaksanaan program ekowisata, perlindungan flora dan fauna, serta dukungan finansial. Penelitian ini menggunakan pendekatan kualitatif. Data diperoleh melalui wawancara mendalam, review dokumen dan observasi objek wisata. Kemudian dilakukan analisis tema dan isi, dan dilakukan triangulasi hasil wawancara mendalam, review dokumen dan observasi. Hasil penelitian menunjukkan kerjasama dalam perlindungan lingkungan di sekitar lokasi wisata baru dilaksanakan oleh salah satu objek wisata dengan Kementerian Lingkungan Hidup dan Kehutanan. Di daerah ini telah terdapat salah satu objek wisata yang menggunakan konsep ekowisata, dan rencana pengembangan ekowisata di situs wisata lainnya. Kebijakan perlindungan flora dan fauna telah dibuat oleh pengelola wisata. Dalam konteks dukungan finansial, pemerintah dan swasta telah mulai terlibat dalam mendukung kelestarian lingkungan. Untuk pengembangan pariwisata lebih lanjut, diperlukan kerjasama yang lebih baik antara pengelola objek wisata dengan pemerintah sebagai stakeholder terbesar untuk mendukung kesuksesan kegiatan wisata sambil mendukung pelestarian lingkungan.
\end{abstract}

Kata kunci: pembangunan berwawasan lingkungan, konservasi lingkungan

\begin{abstract}
Tourism activities will impact the environment, so a commitment is needed to carry out environmental conservation that is tailored to the type of tourist attraction. The concept of sustainable tourism is one of the components used in increasing understanding of the importance of protecting the environment in tourism activities. This is following the regulations made by the Ministry of Tourism and the Government of West Sumatra Province. Environmental conservation indicators are activities to maintain and improve the environmental quality of tourist areas. This study aimed to analyze cooperation activities among stakeholders to preserve the environment, implement ecotourism programs, protect flora and fauna, and financial support. This research uses a qualitative approach. Data were collected using in-depth interviews, document reviews, and observation of tourism objects. Data analysis was carried out by analyzing the themes and contents by triangulating the interviews' results, observing the results, and reviewing the documents. The results showed that cooperation in environmental protection around new tourist sites was carried out by one tourist attraction with the Ministry of Environment and Forestry. In this area, there is already one tourist attraction that uses ecotourism and plans to develop ecotourism in other tourist sites. The policy to protect flora and fauna has been made by the tourism manager. In the context of financial support, the government and private sector have started to get involved in supporting environmental sustainability. For further tourism development, better cooperation between the manager of tourist attractions and the government as the largest stakeholder is needed to support tourism activities' success while supporting environmental conservation.
\end{abstract}

Keywords: environmentally sustainable development, environmental conservation 


\section{PENDAHULUAN}

Dalam ideologi pembangunan berkelanjutan, masyarakat diharapkan dapat memenuhi kebutuhan saat ini tanpa mengorbankan pemenuhan kebutuhan generasi mendatang untuk hidup dengan layak. Konsep ini muncul karena kekhawatiran terjadinya percepatan kemunduran kondisi lingkungan yang disebabkan oleh perilaku yang hanya bertujuan untuk memenuhi kebutuhan tanpa mempertimbangkan dampak negatif terhadap lingkungan di masa yang akan datang (McBride et al., 2013).

Untuk meningkatkan pemahaman pentingnya menjaga lingkungan, diperlukan pemahaman yang baik mengenai kondisi lingkungan yang sedang terjadi di masa ini sehingga dapat meminimalisir kondisi negatif yang dapat berpengaruh di masa yang akan datang. Adanya konsep pariwisata berkelanjutan merupakan salah satu komponen yang digunakan dalam peningkatan pemahaman mengenai pentingnya menjaga lingkungan dalam kegiatan wisata. Konsep pariwisata yang dikaitkan dengan konsep keberlanjutan adalah kegiatan wisata yang mempertimbangkan komponen lingkungan, ekonomi, dan sosial budaya (Wu et al., 2015).

Kebijakan pariwisata di Indonesia diatur oleh Peraturan Menteri Pariwisata Nomor 14 Tahun 2016 tentang Pedoman Destinasi Wisata Berkelanjutan. Dalam peraturan ini dipertimbangkan kriteria lingkungan untuk melaksanakan kegiatan pariwisata (Peraturan Menteri Pariwisata Nomor 14 Tahun 2016 Tentang Pedoman Destinasi Pariwisata Berkelanjutan, 2016). Selain itu pembangunan pariwisata menurut Undang-Undang Nomor 10 Tahun 2009 tentang Kepariwisataan disebutkan bahwa penyelenggaraan pariwisata salah satunya dilaksanakan dengan prinsip memelihara kelestarian alam dan lingkungan hidup (UndangUndang Republik Indonesia Nomor 10 Tahun 2009 Tentang Kepariwisataan, 2009). Dalam Peraturan Daerah Provinsi
Sumatera Barat Nomor 3 Tahun 2014 tentang Rencana Induk Pembangunan Kepariwisataan Provinsi Sumatera Barat tahun 2014-2025, disebutkan bahwa kegiatan pembangunan pariwisata berdasarkan kepada pelestarian lingkungan serta mewujudkan ekonomi hijau (ramah lingkungan) pada setiap kegiatan usaha pariwisata. Selain itu, peraturan ini menyebutkan diperlukan regulasi untuk menjaga daya dukung lingkungan (Peraturan Daerah Provinsi Sumatera Barat Nomor 3 Tahun 2014 Tentang Rencana Induk Pembangunan Kepariwisataan Provinsi Sumatera Barat Tahun 20142025, 2014).

Kegiatan pariwisata di Kabupaten Padang Pariaman berjalan sangat pesat. Pada tahun 2018, pemerintah menargetkan kunjungan wisatawan nusantara dan mancanegara sebanyak 60.000 orang. Akan tetapi, realisasi kunjungan wisata melebihi ekspektasi sebesar 183.600 orang atau $306 \%$ dari target yang ditetapkan. Hal ini membuktikan bahwa kegiatan pariwisata merupakan kegiatan unggulan di Kabupaten Padang Pariaman yang tentunya memiliki dampak terhadap lingkungan. Dari hasil penelusuran kebijakan daerah setempat, belum terdapat kebijakan khusus pro lingkungan untuk mendukung pembangunan berkelajutan, melainkan lebih banyak kepada pengelolaan dan pengembangan pariwisata dari perspektif ekonomi.

Adapun salah satu misi pembangunan Kabupaten Padang Pariaman adalah meningkatkan potensi daya saing daerah melalui pengembangan pariwisata, transportasi, perdagangan, penataan ruang dan pengelolaan lingkungan. Akan tetapi dalam kebijakan pariwisata belum terlihat sinergitas pengembangan destinasi wisata dengan keberlanjutan lingkungan (Pemkab Padang Pariaman 2018).

Salah satu indikator yang diperhatikan dalam kebijakan pariwisata agar sesuai dengan konsep pembangunan berwawasan lingkungan yang berkelanjutan adalah konservasi lingkungan. Indikator ini 
merupakan kegiatan menjaga dan meningkatkan kualitas lingkungan daerah wisata dengan memperhatikan kegiatan kerjasama antar pemangku kepentingan untuk menjaga kelestarian lingkungan, pelaksanaan program ekowisata, perlindungan flora dan fauna, serta dukungan finansial (UNEP and WTO 2008). Oleh karena itu penelitian ini bertujuan untuk mengetahui isu konservasi lingkungan dalam kegiatan pariwisata di Kabupaten Padang Pariaman untuk mencapai pembangunan berwawasan lingkungan yang berkelanjutan.

\section{METODE PENELITIAN}

Penelitian ini menggunakan pendekatan kualitatif, yang digunakan untuk memahami fenomena mengenai suatu hal secara mendalam dan holistik sehingga mengungkapkan bagaimana realita tersebut berjalan sebagaimana adanya. Untuk mendapatkan kebenaran ini, peneliti mencari tahu langsung mengenai objek yang diteliti, dan objek memberikan jawaban langsung kepada peneliti. Data dikumpulkan menggunakan wawancara mendalam, telaah dokumen-dokumen yang berhubungan dengan penelitian, catatan lapangan, foto, video dan rekaman.

Data dikumpulkan melalui wawancara mendalam kepada informan yang dianggap mengetahui seluk beluk penelitian sehingga dapat menjawab pertanyaan sesuai dengan tujuan penelitian. Informan tersebut berasal dari Dinas Pariwisata (2 orang), Dinas Lingkungan Hidup (2 orang), pengelola objek wisata yang merupakan objek wisata yang paling diminati wisatawan (Anai Land, air terjun Nyarai, Pantai Tiram, wisata religi Syekh Burhanuddin), pengelola hotel dan pengelola restoran. Alat pengumpul data yang digunakan adalah pedoman wawancara, formulir catatan wawancara dan voice recorder. Selain itu dilakukan observasi mengenai kondisi lingkungan di beberapa objek wisata di Kabupaten Padang Pariaman.
Data diolah dengan menyalin hasil wawancara ke dalam transkrip wawancara. Setelah itu data direduksi sesuai dengan tema menggunakan matriks agar data yang didapatkan lebih terorganisir. Untuk menjamin validasi data dilakukan triangulasi hasil wawancara, dengan hasil observasi dan telaah dokumen. Analisis penelitian dilakukan dengan teknik analisis tema dan isi (content analysis), yaitu melakukan klasifikasi data hasil penelitian sesuai dengan kesamaan ciri dan dibandingkan dengan teori.

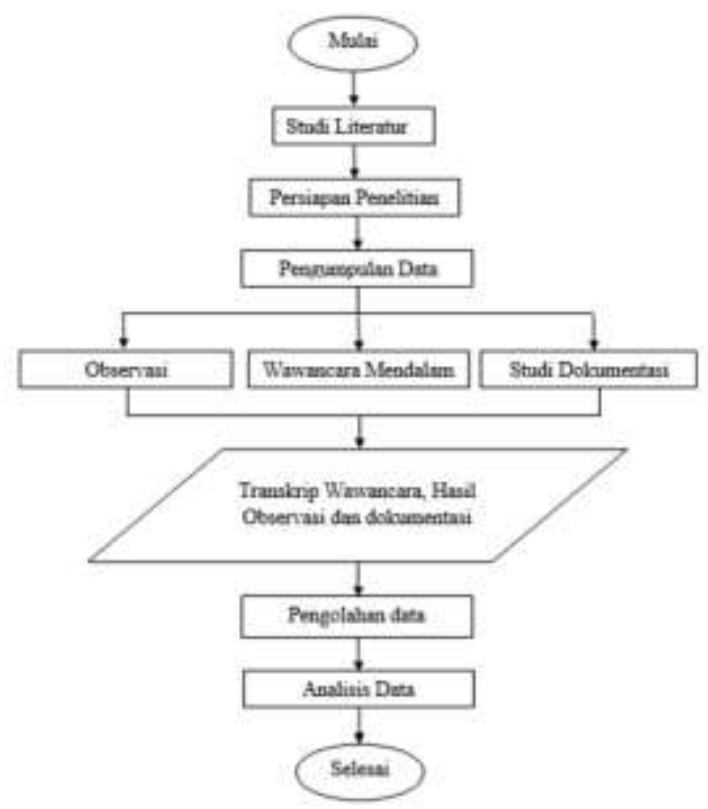

Gambar 1. Kerangka Penelitian

\section{HASIL DAN PEMBAHASAN}

\section{Kerjasama dalam Perlindungan Lingkungan Sekitar Lokasi Wisata}

Dalam isu perlindungan lingkungan di sekitar objek wisata, baru dilaksanakan di objek wisata Nyarai. Di lokasi ini telah terdapat hutan lindung yang dikelola oleh nagari dibawah naungan Dinas Kehutanan. Hal ini untuk menjaga kelestarian hutan dan kegiatan wisata yang berada di wilayah tersebut tetap untuk peruntukannya sembari menjaga kelestarian lingkungan. Untuk objek wisata lainnya baru sebatas himbauan.

"Khusus mungkin wisata kita yang punya dengan hutan lindung itu kita 
artinya minta pedoman minta petunjuk kemudian melalui Dinas Kehutanan." (Inf-1)

"Kalau hutan lindung, memang sudah di jadikan milik nagari dibawah naungan Dinas Kehutanan sendiri. Penelitian yang dilakukan dengan perguruan tinggi akan dibuat MOUnya." (Inf-2)

"Sepanjang pantai itu bisa dikembangkan pariwisata yang mendukung ekosistem yang ada disana, bagaimana intinya orang menikmati ekosistem disana seperti manusianya, tumbunhannya, lingkungannya dan segala macamnya, dan kalupun itu terpaksa harus merusak kami mintak ada penggantinya." (Inf-3)

"Kita kerjasama dengan balai BPSKL balai konservasi ini dia mewadahi Bukit barisan 1 dan berkoordinasi dengan Dinas Kehutanan." (Inf-5)

"Di objek wisata kita belum ada kerjasama tentang itu”(Inf-7)

"Kami belum ada hal semacam itu." (Inf-9)

Kerjasama berbagai pihak diperlukan untuk menjamin kelestarian lingkungan. Kegiatan pariwisata dapat menimbulkan berbagai dampak negatif terhadap lingkungan sekitar karena meningkatnya campur tangan manusia terhadap lingkungan. Hal ini dapat menyebabkan perubahan yang irreversible dalam proses ekologi seperti adanya sumber daya alam yang terdegradasi, struktur vegetasi dan habitat yang terganggu, peningkatan deforestasi dan penurunan kualitas hulu sungai (Bunruamkaew \& Murayama, 2012).

Oleh karena itu diperlukan kerjasama semua pihak terkait untuk melindungi situs wisata termasuk didalamnya dukungan kebijakan dan finansial. Isu yang perlu diperhatikan oleh stakeholder dalam pariwisata berkelanjutan adalah penghormatan terhadap budaya tradisional lokal, penghormatan terhadap gaya hidup lokal, kepatuhan wisatawan terhadap pedoman destinasi, masalah lalu lintas, perusakan lingkungan alam, keberadaan keramaian di destinasi, partisipasi dalam kegiatan budaya, pemahaman budaya, asimilasi ke dalam budaya lokal, efek keseluruhan dari pariwisata, perbedaan manfaat-biaya, dan pengurangan dampak lingkungan (Lee \& Hsieh, 2016).

Badan dan lembaga konservasi perlu menyebarluaskan data terkait kegiatan pariwisata dan pelestarian melalui berbagai cara, seperti booklet informasi, makalah, dan peta. Selain itu, berbagai kesempatan belajar disediakan bagi masyarakat lokal untuk meningkatkan bisnis wisata mereka, memandu wisatawan, menghasilkan pendapatan, meningkatkan keterampilan, meningkatkan keterampilan kepemimpinan, dan melestarikan keanekaragaman hayati.

Dengan melihat berbagai manfaat ini, pemangku kebijakan harus menerapkan wisata sebagai alat utama untuk meningkatkan mata pencaharian dan melestarikan keanekaragaman hayati. Kondisi ini akan meningkatkan jumlah pengunjung, meningkatkan pendapatan dan memberikan insentif ekonomi lebih lanjut untuk pelestarian lingkungan.

\section{Kebijakan Ekowisata}

Daerah ini belum memiliki kebijakan ekowisata yang secara resmi, tetapi pemerintah dan pengelola objek wisata sudah melaksanakan kegiatan-kegiatan menuju konsep ekowisata berpedoman kepada peraturan pengelolaan lingkungan yang ada.

"Kebijakan ekowisata mungkin belum secara tertulis, tetapi lisan sudah ada. Kita arahkan ke beberapa lokasi. Sekarang kita sedang giatnya mengembangkan Green Talao Park di Ulakan dengan mengutamakan 
mangrove dan nipah, itu konsepnya green untuk wisata ini." (Inf-1)

"Cuma dari program program tersirat aja contohnya nyarai yang udah melaksanakan. Kalau kebijakan kerangka hukumnya belum tapi dalam renstra kita sudah ada,di renstra dinas." (Inf-2)

"Kita masih berpedoman pada peraturan pengelolaan lingkungan." (Inf-3)

"Jika ada kegiatan di pariwisata, kami akan masuk kesitu.” (Inf-4)

"Kebijakan ekowisata belum ada. Kita aja yang adop dari internet gitu dan terapkan dilapangan" (Inf-5)

"Kita sudah ada rencana kedepannya." (nf-6)

"Penerapan wisata di tiram saat ini yg berkaitan dengan ekowisata berupa penghijauan." (Inf-7)

Menurut World Tourism Organization (WTO), sejak tahun 1990-an kegiatan pariwisata menunjukkan pergesaran minat dan trend kembali ke alam (back to nature) menjadi kan wisata alam semakin diminati. Hal ini menimbulkan konsep ecotourism yang memberikan ruang yang besar bagi masyarakat sekitar daerah wisata untuk terlibat aktif secara sosial dan ekonomi melalui pemanfaatan kegiatan wisata alam, sambil tetap menjaga lingkungan agar selalu lestari dan berkelanjutan (Insani et al., 2019).

Ekowisata merupakan bentuk pariwisata yang mendukung pembangunan berkelanjutan; khususnya konservasi keanekaragaman hayati, pengentasan kemiskinan, dan peluang usaha. Hal ini dapat berkontribusi terhadap pelestarian lingkungan dan perkembangan masyarakat dan ekonomi suatu bangsa dan seluruh dunia (KC, 2017).
Dengan adanya program ekowisata, diharapkan dapat sekaligus mempromosikan aktivitas terkait keanekaragaman hayati sehingga dapat mendukung pengembangan kepedulian wisatawan serta meningkatkan apresiasi mereka terhadap keanekaragaman hayati (Hausmann et al., 2017).

Terdapat 3 manfaat utama ekowisata bagi peningkatan jangka panjang wilayah setempat, terutama terhadap ekonomi, masyarakat dan budaya, serta lingkungan. Pariwisata dapat lebih ditingkatkan dan dikelola dengan bantuan keterlibatan masyarakat, penyebaran pengetahuan tentang makanan dan kebersihan, dan pelestarian lingkungan (Regmi, 2016).

Pemerintah sebagai stakeholder terbesar dapat berperan untuk mengembangkan potensi ekowisata lebih serius kedepannya, sehingga kawasan yang berpotensi menjadi lebih bernilai dan berbobot.

Beberapa hal yang dapat dilakukan pemerintah adalah dengan membantu promosi yang lebih aktif mengenai ekowisata serta melakukan monitoring dan evaluasi secara berkala untuk menjamin kegiatan wisata berjalan tetap mematuhi prinsip kelestarian lingkungan.

Selain itu, pemerintah dapat memfasilitasi pengembangkan unit-unit ekonomi atau koperasi untuk mendukung penyediaan kebutuhan wisatawan, seperti penyediaan makanan/restoran, toko souvenir, fasilitas MCK, parkir, keamanan, pemandu wisata yang andal (salah satunya dapat berbahasa asing) dan penyediaan penginapan.

\section{Perlindungan Flora dan Fauna}

Dalam perlindungan flora dan fauna di destinasi wisata sudah sangat baik, terbukti dengan adanya kebijakan penanaman tumbuhan oleh pengunjung, dan adanya kesempatan wisata memancing dan mengembalikan ikan tersebut ke kolam pancingan. Selain itu kesadaran untuk perlindungan flora dan fauna sudah ditanamkan sejak dari dini. Pada beberapa objek wisata hal ini sudah diberitahu 
melalui papan pengumuman dan disampaikan secara lisan.

"Pengunjung ada yang kita beri tumbuhan kemudian diberi kesempatan untuk menanam. Pengunjung juga diberi kesempatan untuk ini Menembak ikan kemudian juga diberi kesempatan untuk memancing, tetapi memancing yang ikannya tidak boleh dibawa pulang dan harus dilepas kembali." (Inf-1)

"Masalah edukasi flora dan fauna paling yah lewat spanduk spanduk, slogan slogan paling itu kalau acara khusus itu belum. Di Nyarai punya konsep, jadi setiap pengunjung yang keatas mereka bawa bibit, nantik ditaruh ditanah dan dikasih nama, nantik sudah ada diprogram." (Inf-2)

"Untuk itu kita masuk ke konsep adiwiyata, diajarkan ke sekolah sejak SD sampai SMA. Ini akan meningkatkan kapasitas mereka menjaga lingkungan, termasuk bagaimana menjadi pengunjung yang baik terhadap objek wisata." (Inf-3)

"Untuk itu kita baru melakukan sosialisasi ke sekolah sekolah dan sosialisasi kepada masyarakat agar sadar akan keberlangsungan ekosistem." (Inf-4)

"Kita kayak semacam pemberian papan informasi habis itu edukasi kepada masyarakat, untuk pengunjung kita kan untuk pengunjung ada pemandunya jadi mengingatkan. Di tingkat kelompok kita ada semacam kita ada evaluasi bulanan" (Inf-5)

"Kalau himbauan untuk menjaga belum ada ya." (Inf-6)

"Sebelum adanya pokdarwis mengenai perawatan ada peraturan yang sifatnya lisan saja ke masyarakat setempat contohnya dilarang menggunakan racun ikan." (Inf-7)

Dalam perlindungan terhadap flora dan fauna, lebih difokuskan di sekitar lokasi wisata Air Terjun Nyarai, karena objek wisata ini berada di kawasan hutan lindung. Beberapa jenis flora yang ditemukan di wilayah ini adalah Kelat Simasik (Syzygium verlifolia MIQ), Kelat (Syzygium sp), Kelat Sipisang (Syzygium densiflora DUTHY), Manau (Calamus manan miquel), Kandis (Garcinia atrovorodos), Cubadak air (Artocarpus $s p$ ), Beringin (Ficus benjamina), Rotan (Calamus axillaris), dan tanaman non komersil lainnya. Barangan dan Kandis adalah jenis tanaman yang banyak dimanfaatkan oleh masyarakat sekitar. Buah Barangan direndang bersama pasir untuk dijadikan camilan seperti kacang goreng. Buah kandis dijadikan bumbu masakan yang dikenal dengan nama "asam kandis". Selain itu terdapat tumbuhan obat diantaranya pasak bumi (Eurycoma longifolia), daun biring (obat gatal-gatal "biring") dan situnggang. Sedangkan jenis fauna yang terdapat di daerah ini adalah Ular (Serpentes $s p$ ), Biawak (Varanus $s p$ ), Wie-Wie (Cicadiae), Siamang (Symphalangus syndactylus), kupu-kupu (Rhopalocera) dan lebah hutan (Anthophila) (Putra, 2017).

Hal ini sejalan dengan penelitian sebelumnya yang mengamati bahwa penduduk lokal menggunakan sumber daya yang ada di lingkungan wisata untuk kayu bakar, makanan untuk ternak, dan bahan untuk membuat atap. Selain itu, masyarakat setempat juga menjadikan berbagai buah-buahan musiman, ikan, jamur, biji-bijian, umbi, alang-alang, beri, dan kacang-kacangan untuk makanan sehari-hari (Nyaupane \& Poudel, 2011).

Oleh karena itu, keberadaan flora dan fauna harus tetap terlindungi, dan hal ini membutuhkan pengaturan khusus oleh pengelola objek wisata. Pengelola objek wisata sudah sedemikian rupa memberikan pengarahan kepada pengunjung untuk 
mengurangi risiko ini. Selain itu perlu dibuat zona penyangga untuk melestarikan tumbuhan dan hewan langka, sekaligus meningkatkan standar hidup penduduk, dan meminimalkan konflik yang terkait dengan pemanfaatan sumber daya yang tersedia.

Peran pemerintah dan masyarakat perlu ditingkatkan untuk mendukung perlindungan sumber daya dan strategi konservasi. Untuk masyarakat, kebijakan ini dapat bermanfaat dalam melindungi mata pencaharian dan kebutuhan seharihari. Selain itu, wisatawan dapat menikmati pariwisata tanpa terganggu dengan kerusakan tanaman serta ancaman hewan liar yang terganggu akibat aktifitas wisata.

\section{Dukungan Finansial}

Pendapatan dari retribusi atau karcis masuk objek wisata diserahkan ke PEMDA dan juga dimanfaatkan lagi oleh pengelola. Beberapa objek wisata sudah dikelola oleh swasta dan pengelolaan lingkungannya sudah terjaga dengan baik. Terdapat dukungan pihak swasta untuk membantu kelestarian lingkungan yang ada di beberapa objek wisata

"Sampai sekarang pariwisata kita itu lebih banyak berbasis masyarakat. Sudah ada objek wisata yang dikembangkan oleh pihak swasta" (Inf1)

"Kalau dia itu berbayar, 70:30. 70 untuk pemungut, 30 untuk stor ke PEMDA. Pemanfaatan retribusi itu kembali ke pengelola untuk pelayanan wisata." (Inf-2)

"Sampai saat ini dukungan finansial belum ada" (Inf-4)

"Ada dua, pertama Semen Padang ada memberi penunjuk arah dari Astrada ada seperti ke rumah bibit itu dari Astra." (Inf-5)

\author{
"Objek wisata kita dibiayaai \\ perusahaan swasta." (Inf-6) \\ "Belum ada dukungan finansial dari \\ swasta." (Inf-7)
}

"Kita ada dukungan dana APBN dan APBD. Mulai dari Renovasi Masjid Syekh Burhanuddin sebesar Lebih kurang $50 M$ dan telah terealisir sepanjang tahun 2009-2019 sebanyak 15 M. Sedangkan untuk renovasi Makam Syekh Burhanuddin sendiri direncanakan sebesar lebih kurang 30 $M$ dan sejak 2017-2019 telah terealisasikan sebanyak 4,5 M." (Inf-8)

Penghasilan dari kegiatan pariwisata sebaiknya dimanfaatkan sedemikian rupa untuk mendukung kelestarian lingkungan, khususnya di destinasi wisata. Selain itu, daerah tujuan wisata harus cukup menarik untuk menghasilkan sumber daya keuangan yang memadai dan memberikan insentif bagi masyarakat miskin untuk mengurangi penggunaan sumber daya lingkungan mereka dan mendukung kegiatan konservasi. Selain itu, harus ada investasi pada infrastruktur dan pelatihan untuk meningkatkan kualitas masyarakat lokal yang terlibat dalam kegiatan pariwisata (Narain \& Orfei, 2012).

Kegiatan pariwisata dapat menjadi berkelanjutan jika difokuskan beberapa hal sehingga membutuhkan dukungan finansial yang baik. Kegiatan tersebut adalah peningkatan kualitas lingkungan yang dilakukan terus menerus dan berkelanjutan sehingga wisatawan tertarik untuk berkunjung kembali. Pengembangan kawasan wisata harus diiringi dengan pelestarian dan regenerasi sumber daya alam. Selain itu terdapat keseimbangan antara kebutuhan wisatawan dan perlindungan lingkungan yang akan tercapai jika ada dukungan yang baik untuk kegiatan wisata (Kiper, 2013).

\section{KESIMPULAN}

Kerjasama perlindungan lingkungan di sekitar destinasi wisata telah dilaksanakan di salah satu objek wisata. Di 
kawasan ini terdapat flora dan fauna, dimana tumbuh-tumbuhan banyak dimanfaatkan oleh masyarakat. Pemerintah perlu menjadi regulator untuk mengawasi kegiatan wisata dan segera meresmikan objek wisata yang berkonsep ekowisata. Dukungan finansial diperlukan dengan meningkatkan insentif serta penghasilan dari kegiatan pariwisata sebaiknya juga dimanfaatkan untuk mendukung kelestarian lingkungan.

\section{DAFTAR PUSTAKA}

Bunruamkaew, K., \& Murayama, Y. (2012). Land use and natural resources planning for sustainable ecotourism using GIS in Surat Thani, Thailand. Sustainability, 4(3), 412429.

Hausmann, A., Slotow, R., Fraser, I., \& Di Minin, E. (2017). Ecotourism marketing alternative to charismatic megafauna can also support biodiversity conservation. Animal Conservation, 20(1), 91-100.

Insani, N., A'Rachman, F. R., Ningsih, H. K., \& Rachmawati, A. P. (2019). Pendampingan Masyarakat Dalam Peningkatan Kapasitas Sumber Daya Manusia (SDM) Kepariwisataan: Wisata Bahari Dusun Tlocor, Kecamatan Jabon, Kabupaten Sidoarjo. Jurnal Praksis Dan Dedikasi Sosial (JPDS), 28-35.

KC, A. (2017). Ecotourism in Nepal. The Gaze: Journal of Tourism and Hospitality, 8(1), 1-19.

Undang-undang Republik Indonesia Nomor 10 tahun 2009 tentang Kepariwisataan, 1 (2009).

Peraturan Menteri Pariwisata Nomor 14 tahun 2016 tentang Pedoman Destinasi Pariwisata Berkelanjutan, 1 (2016).
Kiper, T. (2013). Role of ecotourism in sustainable development. InTech.

Lee, T. H., \& Hsieh, H.-P. (2016). Indicators of sustainable tourism: A case study from a Taiwan's wetland. Ecological Indicators, 67, 779-787.

McBride, B. B., Brewer, C. A., Berkowitz, A. R., \& Borrie, W. T. (2013). Environmental literacy, ecological literacy, ecoliteracy: What do we mean and how did we get here? Ecosphere, 4(5), 1-20.

Narain, U., \& Orfei, A. (2012). Biodiversity, nature-based tourism, and jobs. Washington DC: The World Bank.

Nyaupane, G. P., \& Poudel, S. (2011). Linkages among biodiversity, livelihood, and tourism. Annals of Tourism Research, 38(4), 1344-1366.

Peraturan Daerah Provinsi Sumatera Barat Nomor 3 Tahun 2014 tentang Rencana Induk Pembangunan Kepariwisataan Provinsi Sumatera Barat tahun 2014-2025, (2014).

Putra, T. T. (2017). Valuasi Ekonomi Wisata Air Terjun Nyarai di Kabupaten Padang Pariaman. Universitas Andalas.

Regmi, N. (2016). Rural tourism in Nepal: development and sustainability: $A$ Case Study of Parbat District, Nepal.

Wu, W., Zhang, X., Yang, Z., Qin, W., Wang, F., \& Wang, C. (2015). Ecotourism Suitability and Zoning from the Tourist Perspective: a Nature Reserve Case Study. Polish Journal of Environmental Studies, 24(6). 